\title{
DELINEAMENTO DA APLICAÇÃO DE METODOLOGIAS ATIVAS EM UM CURSO TÉCNICO SUBSEQUENTE NA MODALIDADE A DISTÂNCIA.
}

CURITIBA/PR MAIO/2018

\author{
Maristella Gabardo - IFPR/UNICAMP - maris.gabardo@ifpr.edu.br \\ Vania Carla Camargo - IFPR - vania.camargo@ifpr.edu.br \\ Gioconda Ghiggi - IFPR - gioconda.ghiggi@ifpr.edu.br \\ Kriscie Kriscianne Venturi - IFPR - kriscie.venturi@ifpr.edu.br
}

Tipo: Relato de Experiência Inovadora (EI)

Categoria: Métodos e Tecnologias

Setor Educacional: EDUCAÇÃO MÉDIA E TECNOLÓGICA

\begin{abstract}
RESUMO
Este trabalho trata-se de um relato de experiência e tem por objetivo a descrição da construção do curso técnico subsequente em Vendas na modalidade a distância em uma instituição pública federal tendo como delineamento a aplicação de metodologias ativas. Dentre os resultados obtidos temos: a) a conclusão da escrita do PPC do curso; b) o processo seletivo para contratação das equipes de trabalho para implementação e assistência ao mesmo; c) o delineamento e construção da metodologia de aplicação das metodologias ativas no curso; d) a elaboração do curso de formação pedagógica para a implementação das metodologias no curso e e) elaboração do guia do(a) estudante e materiais para o preparo deste no processo de ensino aprendizagem para metodologias ativas. Percebe-se que para utilização das metodologias ativas a descrição do perfil profissional clara e o traçado metodológico condizente são imprescindíveis para o envolvimento de todos, bem como, o protagonismo do(a) estudante em seu processo de aprendizagem.
\end{abstract}

Palavras-chave: Metodologias Ativas. Educação a Distância. Cursos Técnicos subsequentes. 


\section{INTRODUÇÃO}

Apresentamos o percurso realizado para a elaboração de um curso técnico, subsequente, na modalidade a distância. A elaboração coletiva do projeto pedagógico considerou como pressupostos metodológicos, para o curso, as metodologias ativas. $O$ desenvolvimento das ações para a construção do Projeto Pedagógico do curso, estão descritos neste relato.

\section{OBJETIVOS}

Este trabalho trata-se de um relato de experiência e tem por objetivo geral descrever 0 processo da construção de um curso técnico subsequente em Vendas na modalidade a distância, delineado com metodologias ativas em uma instituição pública federal. Como objetivos específicos propomos descrever: a) o processo de escrita do PPC do curso; b) o processo seletivo para contratação das equipes de trabalho para implementação e assistência ao mesmo; c) o delineamento e construção da metodologia de aplicação das metodologias ativas no curso e d) a elaboração do curso de formação pedagógica para a implementação das metodologias ativas no curso bem como a formação do(a) aprendiz para estudar nestas metodologias.

\section{REFERENCIAL TEÓRICO}

$\mathrm{Na}$ busca de melhorias quanto a proposta metodológica para implementação de um novo curso técnico, na modalidade a distância, que respondesse ao nosso propósito institucional e que proporcionasse a autonomia dos(as) nossos(as) estudantes, foram aprofundados os estudos sobre as metodologias ativas. Os cursos até então realizados, na mesma modalidade, apresentavam situações problemas e atividades coletivas a serem desenvolvidas presencialmente, mas era preciso um maior investimento para ressignificar os momentos presenciais articulando estes com os momentos virtuais.

Consideramos, assim como apresenta Fonseca e Neto (2017), metodologias ativas as diversas estratégias de aprendizagem como: "aprendizagem baseada em problemas, problematização, aprendizagem baseada em projetos, aprendizagem por pares (ou peer instruction), design thinking, método do caso e sala de aula invertida" (FONSECA, NETO, 2017, p. 186). Tais estratégias, favorecem a "autonomia do educando, despertando a curiosidade, estimulando a tomada de decisões individuais e coletivas, advindos das atividades essenciais da prática social e em contextos do estudante" Borges e Alencar (2014, p. 120). 
As Metodologias Ativas trazem a perspectiva da participação coletiva e democrática que "visa por meio da reflexão, e do compartilhamento de conhecimento, uma formação do indivíduo como um ser que se forma à medida que se relaciona e se apropria da realidade humana" (BORGES, ALENCAR, 2014, p. 139).

Assim, na construção do curso técnico em Vendas, consideramos esta metodologia como significativa na formação crítica e reflexiva dos nossos(as) estudantes, optando na aprendizagem baseada em projetos. Nesta perspectiva os(as) estudantes trabalham investigando e respondendo questões complexas, problemas ou desafios propostos (FONSECA, NETO, 2017). Este processo envolve: curiosidade, estudos para solucionar os projetos, execução das soluções propostas e avaliação do trabalho realizado (FONSECA, NETO, 2017). É um método que

\footnotetext{
[...] exige construção do conhecimento,o que se torna possível por meio do envolvimento do aluno em todas as etapas do seu desenvolvimento, desde o planejamento, perpassando todo o processo até a avaliação. Essa experiência didática prepararia o aluno para a vivência profissional futura" (FONSECA, NETO, 2017, p. 192).
}

Neste sentido, dialogamos na construção de um currículo que desenvolvesse e potencializasse as habilidades e competências dos(as) nossos(as) estudantes. Assim, o curso Técnico em Vendas, trabalhará na busca de um profissional com habilidades e competências técnicas pessoais para: demonstrar capacidade de liderança e tomada de decisões; saber caracterizar os tipos de clientes; preparar e efetuar a venda de produtos e serviços; exercitar a empatia e saber ouvir o cliente; demonstrar confiança, tenacidade comercial, capacidade de negociação, persuasão e senso ético; demonstrar resiliência e flexibilidade; desenvolver boa comunicação oral e escrita; entre outras.

A seguir, apresentamos o percurso metodológico na construção do Projeto Pedagógico do Curso Técnico em Vendas, subsequente, modalidade a distância.

\section{PROCEDIMENTOS METODOLÓGICOS PARA A CONSTRUÇÃO DO CURSO}

A construção do curso técnico subsequente em Vendas pelo Instituto Federal do Paraná (IFPR) foi motivada por uma demanda proveniente do Ministério de Educação e Cultura (MEC) e é financiado pela Rede E-Tec Brasil por meio da Bolsa-Formação.

O primeiro passo para a construção de um curso no âmbito do IFPR se deu pela escrita do Projeto Pedagógico do Curso (PPC). A escrita deste documento se delineou observando a importância desse curso para as comunidades a serem atendidas, a concepção pedagógica, os objetivos a serem atingidos, a metodologia a ser empregada em sua concepção, a concepção de avaliação, etc. Logo, se deu a elaboração do 
desenho do curso baseado nas ideias que norteiam a educação para o século XXI, com foco em especial na implementação das metodologias ativas.

Para a escrita do PPC, primeiramente foi estabelecida uma comissão de trabalho composta por servidores: docentes, pedagogas e técnicos administrativos em educação. Logo, realizou-se uma consulta a especialistas da área de vendas para a construção e parecer técnico dos objetivos do curso, perfil do egresso, matriz curricular, ementários dos componentes curriculares e referências bibliográficas básicas e complementares. Com o PPC elaborado, este foi submetido à análise e parecer da Pró-Reitoria de Ensino do IFPR.

Após a elaboração do escopo teórico que abrange o cerne do curso, foi elaborada a estruturação da implementação do curso em si. Suas unidades de produção, avaliação de materiais produzidos e de acompanhamento, assim como as estruturas das aulas e dos demais unidades e recursos pedagógicos que estariam disponíveis para os(as) ${ }^{*}$ Professores(as) Formadores(as) $e^{* *}$ Professores(as) Mediadores(as) Presenciais.

Antes de implementar o curso em todo o estado do Paraná foi realizada uma busca nos campi do IFPR e prefeituras para levantar quais teriam interesse em ofertar o curso técnico em Vendas na modalidade a distância. Desta busca foi fechado uma parceria em 14 polos para a oferta do curso.

Para que fosse possível efetivamente construir todos os recursos pedagógicos e administrativos do curso, tais como: gravação de videoaulas, elaboração de atividades e instrumentos de avaliação da aprendizagem do(a) estudante, acompanhamento do(a) aprendiz em todos os processos que um curso exige, de sistemas de registro acadêmico, assessoria técnico-pedagógica, equipes de gestão, equipes de audiovisual, de design educacional entre outros foi realizado um processo seletivo amplamente divulgado. Foram elaborados rígidos critérios para a classificação dos(as) candidatos(as) primando por selecionar os melhores e mais capacitados profissionais estabelecendo para isso os perfis, formação mínima e experiência profissional desejável nos candidatos.

O pagamento dos mesmos se dá pelo fomento público do governo federal Bolsaformação do PRONATEC.

\subsection{Desenho da aplicação das metodologias ativas no curso}

Partindo-se do princípio que as metodologias ativas primam por colocar o estudante 
como protagonista do seu próprio aprendizado, que a construção dos conhecimentos deve ser significativa e com vistas a aplicação prática dos conhecimentos adquiridos e o envolvimento do(a) estudante em todas as etapas do seu desenvolvimento, delineou-se como se daria a aplicação dessas metodologias no curso. Este desenho permeia a construção de conhecimentos, habilidades e competências das mais diversas, dentre elas as pessoais, comunicacionais e técnico-científicas.

Primeiramente, houve a promoção da ambientação da equipe com o embasamento teórico relacionado às metodologias ativas para o início dos trabalhos por meio de uma revisão bibliográfica, buscando como temática a aplicação de metodologias ativas na modalidade de educação a distância. Constatou-se que, embora exista uma ampla gama de estudos publicados sobre metodologias ativas, são poucos os trabalhos sobre a aplicação desta metodologia na modalidade de $\mathrm{EaD}$ de forma sistemática. Dentre eles podemos citar os estudos de Moran (2013) e Oliveira et al.(2015).

O segundo movimento foi o delineamento do desenho da aplicação das metodologias ativas no curso. Ou seja, o caminho metodológico pelo qual o(a) estudante realizaria a construção de seu conhecimento. Este caminho seria composto por atividades síncronas e assíncronas que teriam que ser realizadas de forma individual (online no AVA) e em equipe (em encontros presenciais no polo).

Como exemplos de atividades assíncronas realizadas online no AVA podemos citar: leituras prévias de materiais indicados pelos(as) Professores(as) Formadores(as) dos componentes curriculares, resolução de estudos de caso, responder à perguntas objetivas de múltipla escolha, participação ativa em fóruns com seus colegas e professor presencial. As atividades síncronas são as atividades interdisciplinares realizadas em sala de aula com os demais colegas de turma. Dentre essas atividades podemos citar: elaboração e apresentação de um projeto delimitado sobre um tema que está sendo desenvolvido, participação ativa nos projetos de intervenção no mundo do trabalho junto a empresas e instituições públicas da região onde habita o(a) estudante, etc. Pela inclusão tanto de atividades síncronas como assíncronas, esperasse desenvolver no alunos as diversas competências que compõe o âmbito do trabalho autônomo, tais como a pró-atividade e a organização pessoal, por exemplo, como as relacionadas com as atividades relacionais, como: resolução de conflitos, liderança, divisão de tarefas, etc.

O curso tem duração de 2 anos e foi dividido em 07 módulos. Cada módulo está composto por três componentes curriculares que contém entre si similaridades temáticas e/ou de competências e habilidades que pudessem ser utilizadas em prol do desenvolvimento de um trabalho interdisciplinar. 
Para o desenvolvimento do trabalho interdisciplinar de cada módulo, foram propostas cinco atividades que foram pensadas para que os diversos conteúdos, conhecimentos, habilidades, competências e fatores relacionais pudessem ser trabalhados concomitantemente. Essas cinco atividades foram denominadas: jogos estratégicos, simulador de realidade, júri simulado, construindo alicerces e projeto do módulo.

A seguir no quadro 1, uma breve descrição de cada uma dessas formulações:

\section{QUADRO 1: DESCRIÇÃO DAS METODOLOGIAS ATIVAS ELABORADAS}

\begin{tabular}{|c|c|}
\hline $\begin{array}{l}\text { Metodologia } \\
\text { ativa } \\
\text { interdisciplinar }\end{array}$ & Descrição da metodologia \\
\hline $\begin{array}{l}\text { Casos } \\
\text { interdisciplinar } \\
\text { es }\end{array}$ & $\begin{array}{l}\text { Esta atividade busca desenvolver as habilidades do trabalho em equipe e estimula o estudo individual } \\
\text { do(a) estudante, assim como o compartilhamento do que foi aprendido com os demais colegas, saindo } \\
\text { do papel de receptor passivo para o de agente principal e responsável pelo seu próprio aprendizado. } \\
\text { O(A) Professor(a) Formador(a) deve elaborar/pesquisar um problema a ser resolvido. Este problema } \\
\text { deve ser proveniente de situaçóes reais costumeir amente vivenciadas por profissionais de vendas. } \\
\text { Além disso, espera-se que of(a) Professor(a) Formador(a) consiga direcionar atr avés de perguntas e } \\
\text { questionamentos a condução do estudo de caso, levando o(a) estudante a questionar e repensar a sua } \\
\text { prática (presente ou futura) laboral. }\end{array}$ \\
\hline $\begin{array}{l}\text { Simulador de } \\
\text { Realidade }\end{array}$ & $\begin{array}{l}\text { O(A) Professor(a) isolará um fator da realidade do profissional de vendas e baseado nisso proporá uma } \\
\text { situação real vivenciada pelos profissionais com seus clientes para que os alunos possam experienciá- } \\
\text { la também, como em um laboratório de prática. Esta situação deve trazer um problema, uma situaçãa } \\
\text { ou uma rotina de trabalho a ser solucionado pelo público que assistirá ao teatro. } \\
\text { Os(a) estudantes deverão encenar a situação por meio de um teatro. A situação enviada pelo(a) } \\
\text { professor(a) poderá ser uma situação fechada que deve ser interpretada exatamente como enviada ou } \\
\text { pode ser uma situação aberta na qual cada grupo poderá escolher como irá realizar, montar o roteiro e } \\
\text { enfocar nos aspectos mais relevantes para a sua vivência e região. } \\
\text { Ao final de cada encenação, as demais equipes deverão discutir o teatro apresentado e, pautado no } \\
\text { que foi estudado na semana anterior e ao longo do curso, dev erão opinar sobre possiveis ideias de } \\
\text { atitudes, soluçôes ou novas práticas para serem utilizadas e implementadas nas situaçốes semelhantes } \\
\text { a apresentada. }\end{array}$ \\
\hline $\begin{array}{l}\text { Construindo } \\
\text { alicerces }\end{array}$ & $\begin{array}{l}\text { Consiste em um trabalho em grupos, cujo objetivo é promover um processo de aprendizagem entre os } \\
\text { sujeitos envolvidos, através da construção coletiva de concepçóes, diretrizes, conceitos, etc. } \\
\text { O(A) Professor(a) Formador(a) propóe que os grupos se juntem para discutir um conceito, uma ideia ou } \\
\text { uma concepção. Cada um dos grupos deverá discutir uma ideia diferente. Ao início de cada atividade, } \\
\text { se escolherá um redator chefe que será o mesmo até o final da atividade. Ele será responsável por } \\
\text { anotar todas as ideias e organizar o pensamento e a discussão do grupo em uma cartolina utilizando, } \\
\text { para isso, letras grandes para que todos consigam visualizar o que está sendo construído. A cada } 20 \\
\text { minutos, o restante do grupo deverá dirigir-se ao próximo grupo e ser recepcionado pelo redator chefe } \\
\text { daquele grupo que relatará o que foi discutido pelo(s) grupo(s) anterior(es) e proporá que o novo grupo } \\
\text { acrescente, modifique, delineie e/ou acolha as opiniôes do(s) grupo(s) anteriores. Ao final o redator } \\
\text { apresentará um relato e um resultado da questão discutida por toda a sala ao grupo. Durante esse } \\
\text { processo o(a) Professor(a) Mediador(a) Presencial deverá apoiar e/ou direcionar os grupos para que } \\
\text { eles se aproximem da resposta esperada. }\end{array}$ \\
\hline $\begin{array}{l}\text { Jogos } \\
\text { Estratégicos }\end{array}$ & $\begin{array}{l}\text { Através do desafio de colaboração, individuais e em equipes, e trazendo os princípios dos jogos para a } \\
\text { sala de aula, se consiga desenvolver um ambiente em que os conhecimentos adquiridos durante a } \\
\text { semana sirvam de base para o cumprimento de uma missão ou tarefa. Para esse cumprimento, deve- } \\
\text { se levar em conta os princípios dos jogos: a estratégia, a colaboração, a competição, a tomada, a } \\
\text { análise de risco, o gerenciamento de conflitos, a divisão de tarefas, a lider ança, etc. } \\
\text { Os jogos podem ser relacionados com situações de vendas, de mistério, de estratégia de guerra, de } \\
\text { persuasão, de construção, de desenvolvimento, entre outros e devem estar relacionados a games } \\
\text { digitais, a jogos de tabuleiro, web quests, os jogos de RPG, etc. Podendo ou não ter o apoio das } \\
\text { tecnologias para ser realizado. }\end{array}$ \\
\hline Júri Simulado & $\begin{array}{l}\text { Esta atividade poderá ser trabalhada pela equipe de Professores(as) Formadores(as) tanto com } \\
\text { conceitos quanto com problemas. } \\
\text { O objetivo desta atividade é a percepção dos(as) estudantes aos diversos pontos de vista de um tema. } \\
\text { Desenvolvendo, assim a sua capacidade de visualizar uma questão em sua abrangência, ideologia e } \\
\text { impacto no mundo. Dentre as habilidades a serem trabalhadas temos a de perceber ambos lados de } \\
\text { uma questâo, os argumentos que apoiam essa posição, a discussão sobre os mesmos e como, através } \\
\text { da persuasão e da arqumentação, se conseque desconstruir um ar qumento. }\end{array}$ \\
\hline $\begin{array}{l}\text { Projeto do } \\
\text { módulo }\end{array}$ & $\begin{array}{l}\text { A melhor forma de aprender é ensinando. Considerando isto o projeto do módulo será propor aos } \\
\text { estudantes que ensinem um determinado conteúdo para os colegas de classe. Para construir esta } \\
\text { atividade de ensino ele acaba por construir os conteúdos relativos aos componentes curriculares. } \\
\text { Para isso deverão realizar as sequintes etapas: } \\
? ? \text { Escolher um dos temas disponibilizados pelos } 3 \text { Professores(as) Formadores(as); } \\
? ? \text { Elaboração do conteúdo que comporá a atividade de ensino que farão com a turma; } \\
? \text { Construção de um recurso pedagógico; } \\
? \text { Realização na turma da atividade de ensino. }\end{array}$ \\
\hline
\end{tabular}

O terceiro movimento foi a realização de uma consulta técnica a uma especialista da educação com vasta experiência na aplicação de metodologias ativas para que o modelo fosse avaliado. Esta consulta objetivou auxiliar, orientar e propor melhorias ao 
desenho da aplicação das metodologias ativas previamente apresentado.

\subsection{Elaboração do curso de formação pedagógica para a implementação das metodologias no curso.}

Primando pela qualidade do trabalho pedagógico dos(as) professores(as) que iriam atuar no curso técnico em Vendas, a DSEaD desenvolveu ao final desse processo e ao início da fase de aplicação e implementação, uma capacitação realizada de forma online com momentos síncronos e assíncronos denominada: Formação Pedagógica para Professores(as) Mediadores(as) Presenciais. Esta formação focou no alinhamento e na capacitação dos membros das equipes, coordenadores(as) de curso, assessores pedagógicos e professores formadores. Assim, todos os envolvidos no processo poderiam entender como o curso foi pensado e projetado, os conceitos nos quais ele se pauta e como esses conceitos serão aplicados na prática. Os temas desenvolvidos para o curso foram: conhecer a instituição IFPR, o projeto pedagógico do curso no qual irá atuar e, de forma mais detalhada, as atividades e avaliações que irá desenvolver com os(as) estudantes. O mesmo foi estruturado da seguinte forma:

a) O Projeto Pedagógico de Curso: os(as) professores(as) realizaram uma leitura orientada do documento para se contextualizarem a respeito do

b) O papel do(a) Professor(a) Mediador(a) Presencial.

c) Fóruns.

d) Videoconferência.

e) Avaliação.

Neste espaço de formação pedagógica foram alocados também outros materiais para orientação dos(as) professores(as) na sua atuação diária seu dia, tais como tutoriais de manejo dos sistemas de registro acadêmico, cronogramas e estruturas para a sala de aula. O curso além de formativo é o local que concentra todas as informações pertinentes a aplicação do curso e estarão disponíveis durante todo o período do curso.

\section{CONSIDERAÇÕES FINAIS}

Diante do processo apresentado conseguiu-se elaborar um curso técnico diferenciado e inovador dentro das práticas pedagógicas que estavam sendo utilizadas nos demais 
cursos ofertados, na modalidade a distância, no IFPR.

A utilização de metodologias ativas no desenvolver dos módulos propicia ao(a) estudante ser protagonista de seu processo ensino aprendizagem e torna a apresentação de conteúdos mais atrativa.

No processo destaca-se a preocupação em trabalhar a temática das metodologias ativas com os envolvidos para produção e oferta do curso. Em nosso processo de trabalho entende-se a importância da compreensão por parte de todos os envolvidos referente ao potencial pedagógico das metodologias ativas escolhidas para o sucesso do curso tanto na questão de qualidade como a entrada, permanência e êxito dos(as) estudantes.

Como resultados do processo de trabalho temos: a) a conclusão da escrita do PPC do curso; b) o processo seletivo para contratação das equipes de trabalho para implementação e assistência ao mesmo; c) o delineamento e construção da metodologia de aplicação das metodologias ativas no curso; d) a elaboração do curso de formação pedagógica para a implementação das metodologias no curso e e) elaboração do guia do(a) estudante e materiais para o preparo deste no processo de ensino aprendizagem para metodologias ativas.

Em análise de todos os processos verificou-se que a clareza dos objetivos traçados do perfil profissional que buscamos formar pelo curso técnico subsequente em vendas, bem como, a elaboração das atividades adequadas aos conteúdos e avaliações condizentes são premissas que permitem um processo de qualidade e a busca de profissionais com preparo para o desenvolvimento do trabalho.

Para as próximas etapas pretende-se iniciar um processo avaliativo das metodologias propostas junto aos(as) estudantes e os(as) professores(as) mediadores(as) presenciais. Esse processo de construção não se finda nesta avaliação, visto que dentre os resultados que venham a se apresentar seja necessária uma revisão da proposta estabelecida.

Assim, este processo tem sido valoroso para equipe de ensino visto a diversas leituras e estudos necessários, bem como, o envolvimento e aumento da interação entre professores(as) e estudantes.

\section{REFERÊNCIAS}

BORGES, Tiago Silva; ALENCAR, Gidélia. Metodologias ativas na promoção da 
formação crítica do estudante: o uso das metodologias ativas como recurso didático na formação crítica do estudante do ensino superior. Cairu em Revista,ano 3, n. 4, p.119-143, jul./ago. 2014. Disponível em: <https://bit.ly/2j|7XPB >. Acesso em 20/05/2018.

MORAN, José Manuel. A educação a distância, mais focada em pesquisa e colaboração. In: FIDALGO, Fernando (Org.). Educação a Distância: meios, atores e processos. Belo Horizonte: CAED-UFMG, 2013. p. 39-51. Disponível em: $<$ https://bit.ly/2gRZhU7 >. Acesso em 20/05/2018.

FONSECA, Sandra Medeiros; MATTAR, João. Metodologias ativas aplicadas à educação a distância: revisão de literatura. Revista EDaPECI. São Cristóvão (SE), v.17, n. 2, p. 185-197, mai./ago.2017

OLIVEIRA, Dafylla Kelly Silva et al. A arte de educar na área da saúde: experiências com metodologias ativas. Humanidades \& Inovação, [S.I.], v. 2, n. 1, aug. 2015. ISSN 2358-8322.

Disponível

em:

$<$ https://revista.unitins.br/index.php/humanidadeseinovacao/article/view/60 $>$. Acesso em: 22 may 2018.

\section{Observação: Descrição de termos}

\section{*Professor Formador}

É o sujeito responsável por ministrar o componente curricular estabelecendo os objetivos a serem atingidos, elaboração dos conteúdos do componente por meio de curadoria de conhecimento, elaboração de materiais e recursos pedagógicos bem como atividades de avaliação da aprendizagem do estudantes e os critérios de avaliação.

\section{**Professor Mediador Presencial}

É o sujeito responsável por conduzir as atividades pedagógicas com os estudantes em momentos presenciais e online. Ele media o processo de ensino junto ao estudante em todas as etapas da oferta dos componentes curriculares construindo conhecimentos, avaliando a aprendizagem dos(as) estudantes, contextualizando na prática as realidades regionais trabalhadas nos componentes. 